\title{
Prenatal Diagnosis of Chromosome 22q11.2 Deletions: Experiences in a Single Institution
}

\author{
Yong Hwa Chae', Dong Wook Kwak', Moon Young Kim', So Yeon Park², Bom Yi Lee², Yeon Woo Lee², Young Ho Lee, Mi Jin Song ${ }^{3}$, \\ and Hyun Mee Ryu ${ }^{1,2 *}$ \\ 'Department of Obstetrics and Gynecology, Cheil General Hospital and Women's Healthcare Center, Kwandong University College of Medicine, \\ Seoul, Korea \\ ${ }^{2}$ Laboratory of Medical Genetics, Cheil Medical Research Institute, Cheil General Hospital and Women's Healthcare Center, Seoul, Korea \\ ${ }^{3}$ Department of Radiology, Cheil General Hospital and Women's Healthcare Center, Kwandong University College of Medicine, Seoul, Korea
}

Purpose: This study was designed to determine the frequency and echocardiographic findings of 22 q11.2 deletions in fetuses with cardiac defects on fetal ultrasound or familial backgrounds of 22q11.2 deletions.

Materials and methods: We retrospectively reviewed the medical and ultrasonographic records of 170 fetuses that underwent fluorescence in situ hybridization (FISH) analysis for chromosome 22q11.2 deletions between February 2001 and April 2013.

Results: Among 145 fetuses with cardiac defects, six (4.1\%) had 22q11.2 deletions. Deletions of 22q11.2 were detected in 6 (5\%) of the 120 fetuses with conotruncal defects: 5 (8.9\%) of 56 with tetralogy of Fallot (TOF) and 1 (5.9\%) of 17 with double outlet right ventricle (DORV). No deletions were found in cases of pulmonary atresia, truncus arteriosus, right aortic arch, or transposition of the great arteries. No 22q11.2 deletions were found in non-conotruncal cardiac malformations. Among 25 fetuses with familial backgrounds of 22q11.2 deletions, one (4\%) had a maternally inherited 22q11.2 deletion with no cardiac findings.

Conclusion: Knowledge of the frequency and echocardiographic findings of 22q11.2 deletions might be helpful for prenatal genetic counseling. It is advisable to perform FISH analysis for 22q11.2 deletions in pregnancies exhibiting conotruncal cardiac defects such as TOF or DORV.

Key words: Fluorescence in situ hybridization, 22q11.2 deletions, Conotruncal cardiac malformation, Prenatal diagnosis

\section{Introduction}

Chromosome 22q11 deletions are second only to Down syndrome in frequency among autosomal chromosomal abnormalities, with an estimated incidence of 1 in 4,000 live births. ${ }^{1)}$ Chromosome 22q11 deletions are associated with a wide range of fetal phenotypes, such as DiGeorge syndrome (DGS), velocardiofacial syndrome (VCFS), and conotruncal anomaly facies syndrome (CAFS). ${ }^{2)}$ The major clinical characteristics of these syndromes include cardiac defects, cleft palate, aplasia or hypoplasia of the thymus, facial dysmorphia, immune deficiency, speech-learning disabilities, and psychiatric complications. ${ }^{2)}$ The acronym "CATCH22" (which represents cardiac defects, abnormal facies, thymic hypoplasia, cleft palate, hypocalcemia,

Received: 25 November 2013, Revised: 19 December 2013, Accepted: 20 December 2013, Published: 31 December 2013

*Corresponding author: Hyun Mee Ryu, M.D., Ph.D.

Department of Obstetrics and Gynecology, Cheil General Hospital and Women's Healthcare Center, Kwandong University School of Medicine, 1-19 Mookjung-dong, Jung-gu, Seoul 100-380, Korea

Tel: +82-2-2000-7683, Fax: +82-2-2278-4574, E-mail: hmryu@yahoo.com

Conflict of interest: We declare that we do not have any conflicts of interests.

(c) This is an open-access article distributed under the terms of the Creative Commons Attribution Non-Commercial License (http://creativecommons.org/licenses/by-nc/3.0/) which permits unrestricted non-commercial use, distribution, and reproduction in any medium, provided the original work is properly cited.

(c) Copyright 2013 by the Korean Society of Medical Genetics 
and 22q11 deletion) was proposed in 1993 as an aid for remembering the main features of the syndrome encompassing DGS, VCFS, and CAFS. ${ }^{3,4}$ It was reported that $83 \%$ of fetuses with $22 q 11$ deletions develop cardiovascular abnormalities such as tetralogy of Fallot (TOF), interrupted aortic arch (IAA), truncus arteriosus (TA), and double outlet right ventricle (DORV). ${ }^{5)}$ The clinical phenotypes of DGS, VCFS, and CAFS are caused by the deletions of several nucleotide sequences from the chromosome $22 q 11.2$ band. Chromosome 22q11.2 deletions are easily detected with extremely high accuracy by fluorescence in situ hybridization (FISH) ${ }_{1}^{6,7)}$ a genetic technique that is commonly used for the detection of 22q11.2 deletions in metaphase chromosomes of lymphocytes, amniocytes, or chorionic villi. ${ }^{8)}$ Prenatal echocardiography also plays a very important role for the detection of 22q11.2 deletions because many cardiac abnormalities are associated with this chromosomal mutation. However, there are no reports examining the relationships between chromosome 22q11.2 deletions and sonographic cardiac malformations detected during the prenatal period in Korean patients.

We designed this study to determine the frequency of $22 q 11.2$ deletions in fetuses with cardiac anomalies or familial backgrounds of 22q11.2 deletions, as detected by FISH during the prenatal period, and to evaluate the echocardiographic findings of fetuses with $22 q 11.2$ deletions.

\section{Materials and Methods}

We retrospectively reviewed the medical and ultrasonographic records of 170 fetuses that underwent FISH analysis for chromosome 22q11.2 deletions between February 2001 and April 2013. Of these 170 fetuses, 6 were twins and 158 were single pregnancies.

Either a karyotype or FISH test was performed on fetal cells obtained by chorionic villi sampling ( $N=5)$, amniocentesis ( $N=$ 134), or cordocentesis ( $N=31$ ). FISH tests for 22q11.2 deletions were carried out using a commercially available locus-specific probe of TUPLE1 or N25 (Vysis, Downers Grove, IL, USA).

\section{Results}

A total of 170 fetuses were investigated via FISH analysis with chromosomal studies. Indications used in the fetal genetic study were fetal cardiac defects on echocardiograms $(\mathrm{N}=145)$ including conotruncal cardiac anomalies $(N=120)$ and nonconotruncal cardiac anomalies ( $\mathrm{N}=25)$, and familial backgrounds of possible 22q11.2 deletions ( $\mathrm{N}=25)$ including family histories of 22q11.2 deletions $(\mathrm{N}=7)$, previous history of childbearing with conotruncal cardiac defect $(\mathrm{N}=12)$, and normal fetus of a twin pair with one fetus with conotruncal defect $(\mathrm{N}=6)$ (Table 1).

Table 1. Indications of FISH Analysis for Chromosome 22q11.2 Deletions

\begin{tabular}{lc}
\hline Indication & $N=170$ \\
\hline Positive fetal echocardiographic finding showing cardiac defect & 145 \\
Conotruncal cardiac defect & 120 \\
Non-conotruncal cardiac defect & 25 \\
Genetic or familial background that may include 22q11.2 deletions & 25 \\
Family history of 22q11.2 deletions & 7 \\
Previous history of childbearing with conotruncal cardiac defect & 12 \\
Normal fetus in a twin pair where the other fetus has a conotruncal defect & 6
\end{tabular}

FISH, fluorescence in situ hybridization

Table 2. Characteristic of Fetuses with Karyotypic Anomaly

\begin{tabular}{lrllll}
\hline Case & Age & \multicolumn{1}{c}{ Karyotypic result } & FISH & \multicolumn{1}{c}{ Indication of FISH } & Ultrasound finding \\
\hline 1 & 33 & $47, \mathrm{XX},+21$ & Normal & Positive fetal echocardiogram & TOF small sized PA \\
2 & 31 & $47, \mathrm{XX},+21$ & Normal & Positive fetal echocardiogram & TOF \\
3 & 34 & $46, \mathrm{X}, \mathrm{t}(\mathrm{X} ; 3)(\mathrm{q} 26 ; \mathrm{q} 25.3)$ & Normal & Positive fetal echocardiogram & DORV, TGA type \\
4 & 40 & $45, \mathrm{X}[20] / 46, \mathrm{X}, \mathrm{idic}(\mathrm{Y})(\mathrm{q} 11.22)[12]$ & Normal & Positive fetal echocardiogram & VSD, PS \\
5 & 31 & $46, \mathrm{XX}, \mathrm{t}(3 ; 4)(\mathrm{q} 21 ; \mathrm{p} 12)$ & Normal & Positive fetal echocardiogram & TOF \\
6 & 29 & $47, \mathrm{XX},+\operatorname{mar}[60] / 46,00[48]$ & Normal & Previous TOF baby & Normal \\
\hline
\end{tabular}

TOF, tetralogy of Fallot; DORV, double outlet right ventricle; TGA, transposition of great arteries; PA, pulmonary atresia; VSD, ventriculoseptal defect; FISH, fluorescence in situ hybridization 
There were 6 cases of other karyotypic anomalies: 2 cases of trisomy 21, 46,X,t(X;3) (q26;q25.3), 45,X[20]/46,X,idic(Y)(q11.22) [12] 47,XX, $+\operatorname{mar}[60] / 46,00[48]$ and $46, X X, t(3 ; 4)(q 21 ; p 12)$ (Table 2). There was no chromosome 22q11.2 duplication among 170 fetuses.

Conotruncal cardiac anomalies included TOF $(\mathrm{N}=56)$, RAA $(N=20), D O R V(N=17)$, transposition of the great arteries (TGA; $\mathrm{N}=10)$, pulmonary atresia (PA; $N=9$ ), ventriculoseptal defect (VSD; $N=7$ ), and truncus arteriosus ( $T A ; N=1$ ) (Table 3 ). Nonconotruncal cardiac anomalies included hypoplastic left heart syndrome (HLHS; $N=8)$, coarctation of the aorta ( $\mathrm{CoA} ; \mathrm{N}=7$ ), atrioventriculoseptal defect (AVSD; $N=1$ ), aortic stenosis (AS; $\mathrm{N}=1)$, and others $(\mathrm{N}=7)$. Table 3 shows that 22q11.2 deletions were found in 5 fetuses (8.9\%) with TOF and 1 fetus (5.9\%) with TOF type DORV. Deletions of 22q11.2 were detected in $6(5 \%)$ of 120 fetuses with conotruncal defects. No deletions were found in conjunction with PA, TA, VSD, RAA, or TGA of fetuses with conotruncal malformations. Furthermore, no deletions were found in fetuses with non-conotruncal cardiac malformations.

Table 3. Proportions of 22q11.2 Deletions According to Types of Conotruncal Cardiac Malformation

\begin{tabular}{lcc}
\hline Subtype & Total number & Number of 22q11.2 deletions (\%) \\
\hline TOF & 56 & $5(8.9 \%)$ \\
RAA & 20 & 0 \\
DORV & 17 & $1(5.9 \%)$ \\
TGA & 10 & 0 \\
PA & 9 & 0 \\
VSD & 7 & 0 \\
TA & 1 & 0 \\
Total number (\%) & 120 & $6(5 \%)$
\end{tabular}

TOF, tetralogy of Fallot; RAA, right aortic arch; DORV, double outlet right ventricle; TGA, transposition of great arteries; PA, pulmonary atresia; VSD, ventriculoseptal defect; TA, truncus arteriosus.
Seven fetuses (4\%) of the 170 tested were confirmed to have chromosome 22q11.2 deletions with normal karyotypes (Table 4). Among 145 fetuses with cardiac defects, six (4.1\%) had 22q11.2 deletions: five had sonographic finding of TOF and one had TOF type DORV. Of the 5 fetuses with TOF, only one fetus was revealed to have an additional heart anomaly, which was RAA. Three fetuses showed extracardiac anomalies in addition to TOF: hypoplasia of the thymus, left club foot deformity, and polyhydramnios. Among 25 fetuses with familial backgrounds of 22q11.2 deletions, 1 (4\%) had a maternally inherited $22 q 11.2$ deletion with no cardiac findings (case 7). Of these 7 fetuses, 2 were referred to a tertiary center, and 5 were followed-up loss. The result of following up the mother referred to a tertiary center showed that case 1 as TOF, Cayler cardiofacial syndrome and congenital laryngomalacia and case 6 as TOF with thymic hypoplasia were diagnosed postnatally (Table 4).

\section{Discussion}

Chromosome 22q11 deletion is a genetic abnormality and is the most common interstitial deletion syndrome. ${ }^{10)}$ Most $22 q 11$ deletions are de novo deletions; only 8\% of the deletions are inherited in an autosomal dominant fashion. If one parent is a carrier of the chromosomal deletion, the inheritance rate of phenotypic abnormality is 50\%. ${ }^{11)}$ Deletions in chromosome 22 q 11 have been found in 90\% of patients with DiGeorge syndrome, $70 \%$ of patients with velocardiofacial syndrome and $15 \%$ of patients with isolated conotruncal cardiac defects. ${ }^{111}$ In previous studies, the prevalence of $22 q 11.2$ deletions associated with conotruncal cardiac defects ranges from $1 \%$ to $48 \%{ }^{12)}$ One study reported that deletions of 22q11.2 were detected in $17.9 \%$ of 251 patients with conotruncal defects and that

Table 4. Clinical Characteristics of Fetuses with 22q11.2 Deletions

\begin{tabular}{|c|c|c|c|c|c|}
\hline Case & $\begin{array}{l}\text { Gestational age at sonographic diagnosis } \\
\text { (weeks) }\end{array}$ & Sonographic description of CHD & $\begin{array}{l}\text { Extra-cardiac } \\
\text { sonographic finding }\end{array}$ & Karyotype & Fetal outcome \\
\hline 1 & 22.3 & DORV TOF type & - & $46, X X$ & Refer to a tertiary center* \\
\hline 2 & 21 & TOF, RAA & - & $46, X Y$ & Follow up loss \\
\hline 3 & 20 & TOF & Hypoplasia of thymus & $46, X Y$ & Follow up loss \\
\hline 4 & 20 & TOF & Left club foot deformity & $46, X X$ & Follow up loss \\
\hline 5 & 26 & TOF & - & $46, X X$ & Follow up loss \\
\hline 6 & 25 & TOF & Polyhydramnios & $46, X X$ & Refer to a tertiary center ${ }^{\dagger}$ \\
\hline 7 & 20 & none & - & $46, X Y$ & Follow up loss \\
\hline
\end{tabular}

Follow-up result:

${ }^{*}$ postnatal diagnosis: TOF, Cayler cardiofacial syndrome, and congenital laryngomalacia tpostnatal diagnosis: TOF, thymic hypoplasia

CHD, congenital heart disease; TOF, tetralogy of Fallot; RAA, right aortic arch; DORV, double outlet right ventricle 
the echocardiographic findings of $22 q 11$ deletions were IAA (50\%), TA (34.5\%), TOF (15.9\%), and DORV (5\%). ${ }^{13)}$ Rauch et al. ${ }^{14)}$ reported that the frequency of 22q11.2 deletions in TOF patients was $8 \%(5-13 \%)$. In our sample, deletions of $22 q 11.2$ were detected in 6 (5\%) of 120 fetuses with conotruncal defects: 5 (8.9\%) of 56 with TOF, and 1 (5.9\%) of 17 with DORV.

Although few pathological mechanisms have been described, many non-conotruncal malformations are sporadically associated with 22q11.2 deletions. ${ }^{15)}$ The prevalence of nonconotruncal malformations is only $1 \%$ (0.5-1.4\%), supporting the common recommendation that all children diagnosed with conotruncal malformations be tested for the $22 q 11$ deletions. ${ }^{12)} 22 q 11$ deletions have also been identified in patients with congenital heart defects, including hypoplastic left heart syndrome, heterotaxy syndrome, valvular pulmonary stenosis, and bicuspid aortic valve. ${ }^{16)}$ In our study, we performed chromosomal analysis and FISH analysis in cases for the nonconotruncal cardiac malformation when it was difficult to diagnose fetal echocardiogram definitly. But deletion of 22q11.2 was not detected in fetuses with non-conotruncal defects. FISH analysis in fetuses with non-conotruncal cardiac malformation may not be justified.

Our results agree with those of previous studies showing that the chance of an extracardiac malformation increases in nuchal translucency, polyhydramnios, and IUGR. ${ }^{17)}$ Therefore, the presence of extracardiac malformations can predict $22 q 11.2$ deletions in fetuses with TOF.

A 24\% rate of deletion has been reported postnatally even in patients with apparently isolated RAA. ${ }^{18)}$ Among subtypes of conotruncal cardiac malformation in our sample, 20 fetuses with isolated right aortic arch (RAA) underwent FISH analysis due to concern of chromosome 22q11.2 deletions (Table 3). but the minimal risk of chromosomal anomalies in fetuses with isolated right aortic arch anomalies may justify not performing invasive testing. $^{19)}$

In case 6, fetal karyotyping and FISH test were performed due to TOF detected via sonographic findings. The results of FISH analysis confirmed 22q11.2 deletion. Later, the mother was found to be a carrier of the deletion by FISH performed on metaphase lymphocytes. There was no maternal cardiac malformation, apparent deformity and mental retardation. The mother was referred to a tertiary center. The result of followingup the mother showed her baby was diagnosed as TOF, thymic hypoplasia postnatally and performed TOF total repair at 8month after birth.

It is necessary to emphasize that $22 q 11.2$ deletions are associated primarily with de novo deletions and phenotypic variability. In case 7, a 34-yr-old gravida 3 para 2 woman underwent fetal echocardiography and fetal FISH testing because her first baby died of sepsis due to VSD complications at 7 days after birth and her second pregnancy was terminated due to TOF findings on prenatal echocardiography. The fetus was confirmed to have chromosome 22q11.2 deletions by FISH test, but showed no cardiac anomalies on echocardiography. The mother was also diagnosed with chromosomal deletion by FISH analysis. She did not show unusual facies or known cardiac abnormalities. The patient was followed-up loss at 30 weeks (Table 4). ${ }^{20)}$

Although a limitation of this study is the relatively small number of fetuses with 22q11.2 deletions that were included in our sample, not only was a relationship between prenatal echocardiographic findings and 22q11.2 deletions established, but the prevalence of 22q11.2 deletions in fetuses with TOF was revealed for the first time in a Korean sample. At the same time, our results agree with those of previous studies regarding the frequency of 22q11.2 deletions. Our results suggest that FISH analysis should be considered for the detection of $22 q 11.2$ deletions when TOF is detected on prenatal echocardiography. However, non-conotruncal malformations are not indicated.

Some patients will require FISH analysis for the detection of 22q11.2 deletions, including: 1) couples with family histories of 22q11.2 deletions, and 2) pregnant women with abnormal prenatal echocardiography findings, especially conotruncal cardiac anomalies such as TOF.

However, even if chromosome 22q11.2 deletions are confirmed by FISH analysis, prenatal counseling remains difficult in view of the clinical variability originating from differences in genotypes and phenotypes of patients with 22q11.2 deletions. However, prenatal genetic counseling is helpful for detecting other affected family members and determining the delivery plan.

In conclusion, information regarding the frequency and echocardiographic findings of 22q11.2 deletions might be helpful for prenatal genetic counseling. Our findings indicate that it is advisable to perform FISH analysis for the detection of $22 q 11.2$ deletions in cases where conotruncal cardiac malformations, such as TOF or DORV, are identified on prenatal screening.

\section{References}

1. Oskarsdóttir S, Vujic M, Fasth A. Incidence and prevalence of the $22 q 11$ deletion syndrome: a population-based study in Western Sweden. Arch Dis Child 2004;89:148-51. 
2. Swillen $A$, Vogels $A$, Devriendt $K$, Fryns JP. Chromosome $22 q 11$ deletion syndrome: update and review of the clinical features, cognitivebehavioral spectrum, and psychiatric complications. Am J Med Genet 2000;97:128-35.

3. Wilson DI, Burn J, Scambler P, Goodship J. DiGeorge syndrome: part of CATCH22. J Med Genet 1993;30:852-6.

4. Yamagishi H. The 22q11.2 deletion syndrome. Keio J Med 2002; 51:7788.

5. Motzkin B, Marion R, Goldberg R, Shprintzen R, Saenger P. Variable phenotypes in velocardiofacial syndrome with chromosomal deletion. J Pediatr 1993;123:406-10.

6. Jouannic JM, Martinovic J, Bessières B, Romana S, Bonnet D. Fluorescence in situ hybridization(FISH) rather than ultrasound for the evaluation of fetuses at risk for 22q11.2 deletion. Prenat Diagn 2003;23: 607-8.

7. Levy-Mozziconacci A, Wernert F, Scambler P, Rouault F, Metras D, Kreitman $B$, et al. Clinical and molecular study of DiGeorge sequence. Eur J Pediatr 1994;153:813-20.

8. Cuneo BF. 22q11.2 deletion syndrome: DiGeorge, velocardiofacial, and conotruncal anomaly face syndromes. Curr Opin Pediatr 2001;13: 46572 .

9. Pinkel D, Gray JW, Trask B, van den Engh G, Fuscoe J, van Dekken H. Cytogenetic analysis by in situ hybridization with fluorescently labeled nucleic acid probes. Cold Spring Harb Symp Quant Biol 1986;51:151-7.

10. Scambler PJ. The $22 q 11$ deletion syndromes. Hum Mol Genet 2000;9: 2421-6.

11. Driscoll DA, Budarf ML, Emanuel BS. Antenatal diagnosis of DiGeorge syndrome. Lancet 1991;338:1390-1.
12. Agergaard $P_{\text {, Olesen }} C_{1}$ Østergaard JR, Christiansen $M$, Sørensen KM. Sorensen KM. The prevalence of chromosome 22q11.2 deletions in 2.478 children with cardiovascular malformations. A population-based study. Am J Med Genet A 2012;158A:498-508.

13. Goldmuntz E, Clark BJ, Mitchell LE, Jawad AF, Cuneo BF, Zackai EH, et al. Frequency of 22q11 deletions in patients with conotruncal defects. J Am Coll Cardiol 1998;32:492-8.

14. Rauch R, Hofbeck M, Zweier C, Koch A, Zink S, Trautmann U, el al. Comprehensive genotype-phenotype analysis in 230 patients with tetralogy of Fallot. J Med Genet 2010;47:321-31.

15. Momma K. Cardiovascular anomalies associated with chromosome 22q11.2 deletion syndrome. Am J Cardiol 2010;105:1617-24.

16. Goldmuntz E. DiGeorge syndrome: New Insights. Clin Perinato 2005:32:963-78.

17. Boudjemline Y, Fermont L, Le Bidois J, Villain E, Sidi D, Bonnet D. Can we predict 22q11 staus of fetuses with tetralogy of fallot? Prenat Diagn 2002;22:231-4

18. McElhinney DB, Clark BJ, Weinberg PM, Kenton ML, McDonald-McGinn $D$, Driscoll DA, et al. Association of chromosome 22q11.2 deletion with isolated anomalies of aortic arch laterality and branching. J Am Coll Cardiol 2001;37:2114-9.

19. Galindo A, Nieto O, Nieto MT, Rodríguez-Martín MO, Herraiz I, Escribano D, et al. Prenatal diagnosis of right aortic arch: associated findings, pregnancy outcome, and clinical significance of vascular rings. Prenat Diagn 2009;29:975-81.

20. Oh DC, Min JY, Lee MH, Kim YM, Park SY, Won HS, et al. Prenatal diagnosis of tetralogy of Fallot associated with chromosome 22q11 deletion. J Korean Med Sci 2002;17:125-8. 